ORIGINAL ARTICLE

\title{
Elit futbolcularda alt ekstremite yaralanması sonrası hareket korkusu ve egzersiz öz yeterliliği
}

\author{
Sabriye ERCAN ${ }^{1}$, Zeliha BAŞKURT², Ferdi BAŞKURT², Muhammed BÜYÜKDEMIR², \\ Giray KOLCU ${ }^{3}$, Cem ÇETIN ${ }^{1}$
}

Amaç: Bu çalışmanın amacı, elit erkek futbolcularda alt ekstremite yaralanması sonrası, fiziksel aktiflikte yetersizlik düzeyindeki, hareket korkusu davranışındaki ve egzersiz öz yeterliliğindeki değişimi incelemek; bu faktörlerin yaralanma dönemine göre farklılık gösterip göstermediğini belirlemek idi.

Yöntem: Kliniğimize başvuran, elit erkek futbolcular örneklem grubunu oluşturdu. Sağlıklı ve alt ekstremite yaralanması geçiren erkek futbolculara Fiziksel Aktiflikte Yetersizlik Ölçeği Kısa Form-10, Tampa Kinezyofobi Ölçeği ve Egzersiz Öz Yeterlilik Ölçeği uygulandı.

Bulgular: Çalışmaya 56 erkek futbolcu (yaş: 19,5 $\pm 0,3$ yıl; vücut kütle indeksi: $21,5 \pm 0,2 \mathrm{~kg} / \mathrm{m}^{2}$ ) dahil edildi. Futbolcuların düzenli antrenman süresi $5 \pm 0,1$ gün/hafta ve $89,8 \pm 2,3$ dakika/seans olarak hesaplandı. Herhangi bir kas-iskelet sistemi yaralanması olmayan 19 futbolcu (Grup sağlam) var iken yaralanma geçiren 37 futbolcu (Grup akut=12; Grup subakut=10; Grup $_{\text {persistan }}=15$ ) vardı. Yaralanma geçiren gruplardaki futbolcuların Fiziksel Aktiflikte Yetersizlik Ölçeği sonuçlarının daha yüksek olduğu ve Grup sağlam ile fark oluşturduğu saptandı $(p<0,05)$. Fakat, Tampa Kinezyofobi Ölçeği ve Egzersiz Öz Yeterlilik Ölçeği sonuçlarında gruplar arasında fark belirlenmedi $(p>0,05)$. Yaralanma geçirmiş olan futbolcularda, bu faktörlerin yaralanma dönemine göre göre farklılık göstermediği bulundu $(p>0,05)$.

Sonuç: Elit erkek futbolcularda cerrahi gerektirmeyen alt ekstremite yaralanması sonrası, fiziksel aktiflikte yetersizliği gözlenmiş ancak hareket korkusu davranışında ve egzersiz öz yeterliliğinde değişim olmamıştır.

Anahtar kelimeler: Futbol, Alt ekstremite yaralanması, Yetersizlik, Hareket, Korku, Öz yeterlilik.

\section{Fear of movement and exercise self-efficacy after lower extremity injury in elite football players}

Purpose: Aim of this study is to examine change in disablement in physical activity, fear of movement behavior and exercise self-efficacy after lower limbs extremity injury in elite male footballers; to determine whether these factors differ according to injury period (acute, subacute, persistent).

Methods: Elite male footballers, who applied to our clinic formed the sample group. Male football players who were found to be healthy and had lower extremity injuries were applied The Disablement in the Physically Active Scale, Tampa Kinesiophobia Scale and Exercise Self-Efficacy Scale.

Results: Fifty-six male footballers (age: $19.5 \pm 0.3$ years; body mass index: $21.5 \pm 0.2 \mathrm{~kg} / \mathrm{m}^{2}$ ) were included in the study. Regular training time is calculated as $5 \pm 0.1$ days/week and $89.8 \pm 2.3$ minutes/session. There are 19 players (Grouphealthy) healthy. There are 37 players (Group $p_{\text {acute }}=12$; Group subacute $=10$; Group persistent $=15$ ) suffered injury. It was found that the results of The Disablement in the Physically Active Scale of the footballers in the injured groups was higher and made a difference with the Grouphealthy $(p<0.05)$. However, there was no difference between the groups in the Tampa Kinesiophobia Scale and Exercise SelfEfficacy Scale $(p>0.05)$. It was found that these factors are not different at the injury period after injury in football players suffering from disability $(p>0.05)$.

Conclusion: After the lower extremity injury that did not require surgery in elite male footballers, disablement physical activity was observed, but there was no change in fear of movement behavior and exercise self-efficacy.

Keywords: Football, Lower extremity injury, Disability, Movement, Fear, Self-efficacy.

1: Suleyman Demirel University, Medicine Faculty, Sports Medicine Department, Isparta, Turkey.

2: Suleyman Demirel University, Health Sciences Faculty, Physiotherapy and Rehabilitation Department, Isparta, Turkey.

3: Suleyman Demirel University, Medicine Faculty, Department of Medical Education and Informatics, Isparta, Turkey.

Corresponding Author: Sabriye Ercan: sabriyeercan@gmail.com

ORCID IDs (order of authors): 0000-0001-9500-698X; 0000-0001-7488-9242; 0000-0002-8997-4172; 0000-0002-9982-5058;

0000-0001-8406-5941; 0000-0002-8151-9554.

Received: June 10, 2020. Accepted: November 30, 2020

DOI: $10.15437 /$ jetr.750345 
$\mathrm{F}$ utbol, dünya genelinde en sik tercih edilen spor disiplinlerinin başında yer almaktadır. Futbol disiplinine katılımın artması spor yaralanmalarını da beraberinde getirmektedir.

$\mathrm{Bu}$ nedenle futbolcularm yaralanma bölgelerini ve yaralanma siklıklarını belirlemeye yönelik birçok araştırma yapılmıştır. ${ }^{1,2} \mathrm{Bu}$ araştırmaların sonuçlarına göre en sık alt ekstremite bölgesine ait kasiskelet sistemi yaralanmalarının oluştuğu belirlenmiştir. ${ }^{1,2}$ Spor yaralanmalarına ait ayrıntılı verilerin bilinmesi, yaralanmadan sonraki tedavi sürecine ve spora geri dönüş programlarına yön verilmesini sağlamaktır.

Spor yaralanmalarına bağlı kas-iskelet sistemi sorunları, sıklıkla ağrı ve fiziksel aktivitede yetersizlik ile kendini göstermektedir. Benzer klinik ciddiyette yaralanma geçirmesine rağmen fiziksel, biyolojik, kognitif, davranışsal, sosyal ve mesleksel faktörlere göre sporcuların ağrı yanıtının değişiklik gösterebildiği bir gerçektir. ${ }^{3}$ Diğer taraftan kas iskelet sistemi yaralanması sonrasında; düşük öz yeterlilik, hareket korkusu (kinezyofobi), katastrofi, anksiyete ve depresyon gibi ağrı ilişkili korkunun ve olumsuz duygu durumunun gelişebileceği bilinmektedir. ${ }^{4,5}$

Öz yeterlilik, kişinin istenen sonucu elde etmek için gereken davranışı gerçekleştirebileceğine dair kişisel inancını ifade etmektedir. ${ }^{6,7}$ Öz yeterliliğin yükselmesi, davranışı sürdürebilmeyi kolaylaştırmaktadır. Egzersize devamlılık ve yeterlilik bağlamında değerlendirdiğimizde; yüksek öz yeterlilik fiziksel aktivitenin sürdürebilirliğini, spor yaralanması gelişmesi halinde tedaviye uyumu arttırmaktadır. ${ }^{7,8}$ Hareket korkusu ise ağrıya ve tekrar yaralanmaya karşı oluşan hassasiyetten kaynaklanan, aktivite ve harekete karşı geliştirilen kaygı durumu olarak tanımlanmaktadır.9,10 Yaralanma sonrası hareket korkusu geliştiğinde tedaviye karşı direnç ve uyum sorunları ile karşılaşılmakta ve spora geri dönüş süreci uzayabilmektedir. ${ }^{11}$

Hem öz yeterliliğin hem de hareket korkusunun seviyesi, egzersiz temelli rehabilitasyonların başarısı için prognostik olmaktadır. ${ }^{12}$ Ayrıca her iki faktör de yaralanma kaynaklı yetersizliğin prediktörü olarak görülmektedir. ${ }^{13} \quad \ddot{\mathrm{O} z}$ yeterlilik ve hareket korkusu ayrı ayrı, tedavi başarısı açısından öngörülebilir sonuçlar verse de Denison vd.'nin çalışmasında 'yüksek öz yeterlilik-düşük hareket korkusu', 'düşük öz yeterlilik-düşük hareket korkusu' ve 'düşük öz yeterlilik-yüksek hareket korkusu' şeklinde sinıflandırılan hasta gruplarında farklı klinik yönetim stratejilerinin uygulanması gerektiği vurgulanmıştır. ${ }^{5} \mathrm{Bu}$ bilgiler ışı̆̆ında, sporcuların rehabilitasyon süreçlerinde öz yeterlilik ve hareket korkusu düzeylerinin tespit edilip tedavi stratejisi geliştirmenin gerekliliği açıkça ortadadır.

Biyopsikososyal modele ve Sağllğı Geliştirme Modeli'ne göre değerlendirildiğinde, yaralanma kaynaklı ağrıdan sonra gelişen yetersizlik/sakatlık, öz yeterlilik ve hareket korkusu klinik yönetim ile modifiye edilebilen faktörlerdir.5,6,14,15 Daha önce yapılan çalışmalarda, bu faktörlerin etkisi sıklıkla

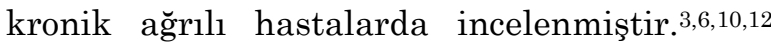
Kronik ağrı dışındaki ağrılı durumlarda öz yeterliliğin ve hareket korkusunun değerlendirildiği çalışma sayısının kısıtlı olduğu görülmüştür. ${ }^{11,16} \quad$ Literatür incelemesi sonucunda, profesyonel düzeydeki sporcuların cerrahi gerektirmeyen kas-iskelet sistemi yaralanmaları sonrasındaki egzersiz öz yeterliliği ve hareket korkusunun değerlendirildiği bir çalışmaya rastlanmamıştır. ${ }^{16}$ Bununla beraber, bu faktörlerin sporcunun spora devamlılığ için önemli olduğu bilinmektedir. Kas-iskelet sistemi yaralanmasının evresine göre egzersiz öz yeterliliği ve hareket korkusu düzeylerinde farklılık oluşup oluşmadığının bilinmesi, sportif rehabilitasyonun kişiye ve hastallk sürecine göre modifiye edilmesini sağlaması açısından önem arz etmektedir. Olasıdır ki bugüne kadar göz ardı edilmiş olan bu müdahale, tedavi başarısını ciddi düzeyde etkileyebilecektir.

$\mathrm{Bu}$ çalışmanın amacı, elit erkek futbolcularda alt ekstremite yaralanması sonrası fiziksel aktiflikte yetersizlik düzeyindeki, hareket korkusu davranısındaki ve egzersiz öz yeterliliğindeki değişimi incelemek; incelenen faktörlerin yaralanma dönemine göre farklılık gösterip göstermediği belirlemek idi.

\section{YÖNTEM}

Çalışma, Süleyman Demirel Üniversitesi Klinik Araştırmalar Etik Kurulu tarafından 
onaylandı (30 Nisan 2020 tarihli, 127 numaralı karar). Çalışma, Helsinki Deklarasyonu 2008 prensiplerine uygun olarak yürütüldü. Kliniğimize, bir yıl boyunca başvuran Tegner Aktivite Düzeyi 8-9 seviyesinde olan tüm elit erkek futbolcular örneklem grubunu oluşturdu. Kadın futbolcular, alt ekstremite dışında herhangi bir vücut bölgesinde yaralanması olanlar, muayene sonrasinda cerrahi tedaviye karar verilenler, son 2 yılda alt ekstremite cerrahisi geçirenler, postoperatif dönemde olanlar çalışmadan dışlandı. Herhangi bir kasiskelet sistemi yaralanmasi olmayan lisans vizesini yenilemek için spora katılım muayenesi yapılmış sağlıklı erkek futbolculara ve spor yaralanması şikayeti ile gelip muayenesinde, alt ekstremite yaralanması geçirdiği tespit edilip konservatif tedavi uygulanan (cerrahiye ihtiyaç duyulmayan) erkek futbolculara yüz yüze görüşme tekniği ile aşağıda belirtilen ölçekler uyguland. Futbolcuların sosyodemografik özellikleri ve (varsa) yaralanmalarına ait klinik ayrıntıları kaydedildi.

\section{Uygulanan Ölçekler}

Tegner Aktivite Düzeyi: Bu puanlama sisteminde kişilerin aktivite düzeyleri 0 ile 10 arasında puanlanmakta, puanın yükselmesi aktivitenin arttığına işaret etmektedir. Sakatlık durumunda 0 puan verilir iken ulusal ya da uluslararası müsabakalara katılan futbolcular 10 puan almaktadır. Bu skorlama sistemine göre 6-10 puan seviyesinde olan kişiler, rekreasyonel veya müsabakalara katılacak düzeyde profesyonel sporcu olmaktadır. ${ }^{17}$

Fiziksel Aktiflikte Yetersizlik Ölçeği (Kısa Form-10), fiziksel olarak aktif popülasyonun fiziksel ve mental durumunu değerlendiren, toplam 10 sorudan oluşan bir ölçektir. Ölçeğin 'Bozukluklar Özet Bileşeni, Fonksiyonel Kısıtlllıklar Özet Bileşeni, Yaşam Kalitesi Özet Bileşeni' olmak üzere 3 alt boyutu bulunmaktadır. Bozukluklar Özet Bileşeni alt boyutunda ağrı, hareket ve kassal fonksiyonlar; Fonksiyonel Kisitlllıklar Özet Bileşeni alt boyutunda stabilite, yön değiştirme ve beceri performansı; Yaşam Kalitesi Özet Bileşeni alt boyutunda ise 4 madde ile iyilik hali irdelenmektedir. Ölçek, 5'li likert ölçeğine puan verilerek cevaplanmaktadır. Ölçekte negatif soru bulunmamakta ve her bir soruya verilen puanlar toplanmakta, alt boyut puanlarının toplamı, toplam puanı vermektedir. Ölçekten alınan puanın yükselmesi fiziksel aktiflikte yetersizliğin arttığını ifade etmektedir. ${ }^{18}$ Ölçeğin Türkçe uyarlama çalışması tarafımızca yapılmış olup klasik test kuramı ile güvenirlik analizinde Cronbach alfa değeri 0,91 ve genellenebilirlik kuramı ile güvenirlik analizinde G-katsayısı 0,91 olarak bulundu.

Fiziksel Aktiflikte Yetersizlik Ölçeği (Kısa Form-10)'nin geliştirilme aşamasında kullanılan yaralanma dönemleri (akut, subakut, persistan) tanımlaması ve sinıflaması, çalışmamızdaki futbolcuların yaralanma dönemlerini sınıflamak için kullanıldı. ${ }^{18}$

Tampa Kinezyofobi Ölçeği, ağrılı bireylerin hareket korkusunu belirlemek amaciyla geliş̧irilmiş bir değerlendirme aracıdır. Ölçek, 17 sorudan oluşmaktadır. Her bir soruya kesinlikle 'katılmiyorum (1 puan), katılmiyorum (2 puan), katıliyorum (3 puan) ve kesinlikle katılıyorum (4 puan)' şeklinde cevap verilebilmektedir. Ölçekteki $4,8,12$ ve 16 numaralı soru ters soru niteliğindedir. Puanlama tüm sorulara verilen puanların toplanması ile hesaplanmakta, ölçekten en az 17 en çok 68 puan alınabilmektedir. Ölçeğin Türkçe geçerlik ve güvenirlik çalışması yapılmıştır. ${ }^{19}$

Egzersiz Öz Yeterlilik Ölçeğgi, egzersize karşı gösterilen öz yeterlilik düzeyini tespit etmek için geliştirilmiştir. Ölçek 18 sorudan oluşmaktadır. Her bir soruya 0 (hiç yapılamaz) ila 100 (kesin yapılabilir) arasinda 10'lu kesme noktaları bulunan puanlama yapılması beklenmektedir. Ölçekte ters soru yoktur. Ölçekten \%0-100 arasinda puan alınabilmektedir. Ölçeğin Türkçe geçerlik ve güvenirlik çalışması yapılmıştır. ${ }^{20}$

İstatistiksel analiz

Veriler, SPSS v 23 paket programı ile analiz edildi. Sıklık değerlendirmeleri ve tanımlayıcı analizler yapıldıktan sonra ShapiroWilk testi ile grupların normal dağılıma uygunluğu test edildi. Normal dağılım sağlanan parametrelerde varyansin homojenlik durumuna göre Bonferroni ya da Tamhane's T2 düzeltmeli One Way ANOVA testi, normal dağılımın sağlanamadığı parametrelerde ise Monte Carlo düzeltmeli Kruskal Wallis testi yapıldı. Yaralanma bölgeleri açısından farkın olup olmadığ ki-kare testi ile incelendi. Veriler ortalama \pm standart hata olarak sunuldu. P değeri 0,05 düzeyinde anlamlı kabul edildi. 


\section{BULGULAR}

Çalışma süresini kapsayan dönemde, 29 futbolcu araştırmaya dahil olma kriterlerini karşılamadığı için dışlandı. Çalışmaya Tegner Aktivite Seviyesi $8(n=12)$ ve $9(n=44)$ düzeyinde olan 56 erkek futbolcu (yaş: 19,5 $\pm 0,3$ yll; vücut kütle indeksi: $\left.21,5 \pm 0,2 \mathrm{~kg} / \mathrm{m}^{2}\right)$ dahil edildi. Futbolcuların düzenli antrenman süresi $5 \pm 0,1$ gün/hafta ve $89,8 \pm 2,3$ dakika/seans olarak hesaplandı. Herhangi bir kas-iskelet sistemi yaralanması olmayan 19 futbolcu (Grup sağlam) var iken yaralanmadan sonraki 0-72. saatte olan 12 (Grupakut), 3.gün 1.ayda olan 10 (Grup subakut), 1.-6.ay arasinda olan 15 (Gruppersistan) futbolcu bulundu.

Gruplara göre Tegner Aktivite Düzeyi, yaş, vücut kütle indeksi ve düzenli antrenman süresi değerlerinde fark tespit edilmedi $(p>0,05)$, (Tablo 1).

Grup Akut'taki sporcular 6 strain, 3 sprain, 3 spazm; Grup Subakut'taki sporcular 4 strain, 4 sprain, 1 fasiitis, 1 fraktür; Gruppersistan'daki sporcular 1 strain, 7 sprain, 2 meniskopati, 3 tendinopati, 2 femoroasetabular impingement sendromu tanısı aldı. Alt ekstremite yaralanması olan futbolcularda yaralanma bölgeleri açısından gruplar arasında fark belirlenmedi ( $p=0,3)$, (Tablo 2 ).

Tüm futbolcular değerlendirildiğinde; Fiziksel Aktiflikte Yetersizlik Ölçeği toplam puanı 21,5 $\pm 1,3$; ölçeğin Bozukluklar Özet Bileşeni $7 \pm 0,5$ puan, Fonksiyonel Kısitlllıklar Özet Bileşeni $6,6 \pm 0,5$ puan ve Yaşam Kalitesi

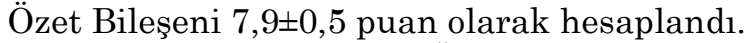

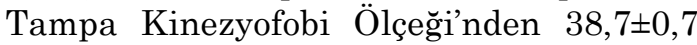
puan, Egzersiz Öz Yeterlilik Ölçeği'nden ise $72,8 \pm 2$ puan alındı.

Yaralanmanın hareket korkusuna ve egzersiz öz yeterliliğinde fark oluşturup oluşturmadığını değerlendirmek için futbolcular gruplara ayrılıp analiz edildiğinde Fiziksel Aktiflikte Yetersizlik Ölçeği (Toplam puan, $\mathrm{p}=0,0001$; bozukluklar özet bileşeni, $\mathrm{p}=0,0001$; fonksiyonel kısıtlılıklar özet bileşeni $\mathrm{p}=0,0001$; yaşam kalitesi özet bileşeni, $\mathrm{p}=0,003$ ) sonuçlarında fark var iken Tampa Kinezyofobi Ölçeği $(p=0,4)$ ve Egzersiz Öz Yeterlilik Ölçeği $(\mathrm{p}=0,4)$ sonuçlarında gruplar arasında fark belirlenmedi. Fiziksel Aktiflikte Yetersizlik Ölçeği’nin toplam puan, Bozukluklar Özet Bileşeni puanı, Fonksiyonel Kısıtlılıklar Özet
Bileşeni puanı ve Yaşam Kalitesi Özet Bileşeni puanı bağlamında gruplar arasındaki fark Grupsağlam ve diğer gruplar arasında oluştu. Bu farklılık, yaralanma geçiren futbolcuların fiziksel aktiflikte yetersizlik düzeylerinin daha yüksek olduğunun göstergesi olarak değerlendirildi. Ayrıca Bozukluklar Özet Bileşeni puanı Grup subakut ve Grup persistan arasında da fark oluşturdu (Tablo 3).

\section{TARTIŞMA}

Çalışmamızda, cerrahi gerektirmeyen alt ekstremite kas-iskelet yaralanması geçiren elit erkek futbolcularda yaralanma sonrasinda fiziksel aktiflikte yetersizlik gelişmesine rağmen bu durumun egzersiz öz yeterliliği ve hareket korkusu bağlamında fark oluşturmadığ tespit edildi.

Birçok insan, yaşamları boyunca en az bir kez kas-iskelet sistemi sorunu ve ağrısı ile karşı karşıya kalmaktadır. ${ }^{3} \mathrm{Bu}$ sistemin sorunları sıklıkla ağrı ve fonksiyonlarda yetersizlik ile kendini göstermektedir. ${ }^{3}$ Sporcular ve özellikle futbolcular açısından değerlendirdiğimiz de kas-iskelet sistemi sorunlarmın sezon boyunca tedavi ihtiyacını en sık oluşturan patolojiler olduğu bilinmektedir.1,2 Yaralanma sonrasında yaralanmanın ciddiyetine göre değişmekle birlikte az ya da çok fiziksel fonksiyonlarda yetersizlik gelişimi beklenen bir durumdur. Çalışmamızda elde ettiğimiz Fiziksel Aktiflikte Yetersizlik Ölçeği verileri de bunu doğrular niteliktedir.

Yaralanma geçiren bir sporcunun sağlıklı bir şekilde spora geri dönüşünü sağlamak için bir an önce tedaviye başlanması gerekmektedir. Kas-iskelet sistemi yaralanmalarının ve ağrilarının tedavisinde, erken evrede uygulanan kontrollü koruyucu yaklaşım sonrasında çoğunlukla egzersiz temelli tedaviler planlanmaktadır.,411,12 Fiziksel egzersiz ve kasiskelet sistemi ağrıları; egzersize/spora, stres vb. gibi faktörlere, iş ile ilişkili fiziksel yüklenmeye bağlıdır. Egzersiz sonrasında ağrının artması ve kaslarda geç başlangıçlı hassasiyet gelişimi beklenen bir yanıttır. Öte yandan kas-iskelet sisteminde ağrı bulunan bireylerin ağrıdan kaçınma davranışı sergileyebilecekleri, dolayısıyla hareket korkusu ve öz yeterlilikte kayıp yaşanabileceği tanımlanmıştır. ${ }^{12}$ Literatürdeki çalışmaların, 
Tablo 1: Sosyodemografik veriler ve antrenman bilgileri.

\begin{tabular}{lccccc}
\hline & Grup Akut & Grup Subakut & Grup Persistan & Grup Sağlam & \\
& $(\mathrm{N}=12)$ & $(\mathrm{N}=10)$ & $(\mathrm{N}=15)$ & $(\mathrm{N}=19)$ & \\
& $\mathrm{X} \pm \mathrm{SD}$ & $\mathrm{X} \pm \mathrm{SD}$ & $\mathrm{X} \pm \mathrm{SD}$ & $\mathrm{X} \pm \mathrm{SD}$ & $\mathrm{p}^{* *}$ \\
\hline Yaş (yIl) & $19,1 \pm 0,4$ & $20,5 \pm 0,9$ & $20,3 \pm 0,8$ & $19,5 \pm 0,1$ & 0,1 \\
Vücut kütle indeksi $\left(\mathrm{kg} / \mathrm{m}^{2}\right)$ & $21,3 \pm 0,3$ & $21,4 \pm 0,5$ & $20,9 \pm 0,2$ & $22,1 \pm 0,5$ & 0,1 \\
Düzenli antrenman süresi (gün/hafta) & $4,8 \pm 0,3$ & $5 \pm 0,3$ & $4,8 \pm 0,1$ & $5,4 \pm 0,2$ & 0,2 \\
Antrenman seansı (dakika) & $94,2 \pm 4,7$ & $81 \pm 4,6$ & $90,7 \pm 7,2$ & $91,1 \pm 0,7$ & 0,1 \\
Tegner Aktivite Düzeyi $(8 / 9, \mathrm{n})$ & $2 / 10$ & $2 / 8$ & $2 / 13$ & $6 / 13$ & 0,6 \\
\hline
\end{tabular}

**: One Way ANOVA testi (vücut kütle indeksi) veya Monte Carlo düzeltmeli Kruskal Wallis testi (yaş, düzenli antrenman süresi, antrenman seansı, Tegner aktivite düzeyi).

Tablo 2: Yaralanma bölgeleri.

\begin{tabular}{lcccc}
\hline & Grup Akut & Grup Subakut & Grup Persistan & \\
& $\mathrm{n}(\%)$ & $\mathrm{n}(\%)$ & $\mathrm{n}(\%)$ & $\mathrm{p} * *$ \\
\hline Ayak/Ayak parmakları & $-(0)$ & $2(20)$ & $1(6,7)$ & \\
Ayak bileği & $6(50)$ & $-(0)$ & $4(26,7)$ & \\
Baldır & $2(16,7)$ & $1(10)$ & $1(6,7)$ & \\
Diz & $1(8,3)$ & $5(50)$ & $6(40)$ & 0,3 \\
Kasık bölgesi & $2(16,7)$ & $1(10)$ & $2(13,3)$ & \\
Kalça/Uyluk & $1(8,3)$ & $1(10)$ & $1(6,7)$ & \\
\hline
\end{tabular}

**: Ki-kare testi.

Tablo 3: Gruplara göre uygulanan anketlerin sonuçları.

\begin{tabular}{lccccc}
\hline & Grup Akut & Grup Subakut & Grup Persistan & Grup Sağlam \\
& $X \pm S D$ & $X \pm S D$ & $X \pm S D$ & $X \pm S D$ & $p^{* *}$ \\
\hline Tampa Kinezyofobi Ölçeği puanı & $38 \pm 1,5$ & $41,3 \pm 1,4$ & $38,5 \pm 1$ & $37,9 \pm 1,6$ & 0,4 \\
Egzersiz Öz Yeterlilik Ölçeği puanı & $68,1 \pm 4,2$ & $71,4 \pm 4,9$ & $78,3 \pm 2,9$ & $72,3 \pm 3,9$ & 0,4 \\
FAYÖ-Toplam puan & $25,9 \pm 2,7^{\text {a }}$ & $30,4 \pm 2,5^{\text {a }}$ & $24,1 \pm 1,7^{\text {a }}$ & $12 \pm 0,7^{\mathrm{b}}$ & $<0,001$ \\
FAYÖ-Bozukluklar Özet Bileşeni & $8,9 \pm 1,1^{\text {a }}$ & $10,5 \pm 0,7^{\text {ac }}$ & $7,7 \pm 0,7^{\text {ad }}$ & $3,3 \pm 0,2^{\mathrm{b}}$ & $<0,001$ \\
FAYÖ-Fonksiyonel Kısıtlııklar Özet Bileşeni & $8 \pm 1,3^{\text {a }}$ & $10,4 \pm 0,9^{\text {a }}$ & $7,5 \pm 0,7^{\text {a }}$ & $3,1 \pm 0,1^{\mathrm{b}}$ & $<0,001$ \\
FAYÖ-Yaşam Kalitesi Özet Bileşeni & $9 \pm 1,2^{\text {a }}$ & $9,5 \pm 1,2^{\text {a }}$ & $8,9 \pm 1^{\text {a }}$ & $5,6 \pm 0,7^{\mathrm{b}}$ & $0,003^{*}$ \\
\hline
\end{tabular}

FAYÖ: Fiziksel Aktiflikte Yetersizlik Ölçeği. **: One Way ANOVA testi (Tampa Kinezyofobi Ölçeği) veya Monte Carlo düzeltmeli Kruskal Wallis testi (Egzersiz Öz Yeterlilik ölçeği, FAYÖ). *: Gruplar arasında istatistiksel anlamlı fark. a b: Grup Sağlam ve diğer gruplar arasında fark. $c$, d: Grup Subakut ve Grup Persistan arasında fark.

ağrıdan sonra gelişebilecek olan bu etkileri çoğunlukla kronik kas-iskelet sistemi ağrısı yaşan bireylerde ve ön çapraz bağ cerrahi geçirmiş sporcularda incelediği gözlemlenmiş̧tir. 3,6,9,10,12,21,22 Çalışmamız, sporcuların cerrahi gerektirmeyen kas-iskelet sistemi sorunlarından sonraki dönemlerini inceleyerek literatürdeki bu eksiği gidermektedir. Sonuçlarımıza göre, yaralanma sonrası fiziksel aktiflikte yetersizlik gelişmesine rağmen hareket korkusu ve egzersiz öz yeterliği değişimi yaşanmamıştır. Bu durum, sporcu olan bireylerin kas-iskelet sistemi sorunlarina verdikleri psikolojik yanıtların diğer 
bireylerden farklılı gösterebileceğinin göstergesidir.

Perrot vd., kas-iskelet sistemi ağrısı tanısı ile fizik tedavi alan bireylerdeki hareket korkusunu incelediklerinde; yaşı ileri olanların (50 yaş ve üzeri), daha az fiziksel aktivitede bulunanların, daha fazla ağrı hissedenlerin ve ağrıyı daha az kabullenenlerin daha yüksek seviyede hareket korkusu yaşadıklarını tespit etmiştir. ${ }^{11}$ Cinsiyetin hareket korkusu konusunda etkili olup olmadığının değerlendirildiği bir diğer çalışmada ise kronik ağrilı erkeklerin benzer ağriya sahip kadınlardan daha fazla hareket korkusu yaşadıkları belirlenmiştir. Diğer taraftan kadın cinsiyet içerisinde genç olanların daha fazla ağrl, hassasiyet, hareket korkusu ve fonksiyonel yetersizlik yaşadığı saptanmıştır. ${ }^{10}$ Çalışmamızda, yaş, cinsiyet ve fiziksel aktivite seviyesi homojen olduğu için bu faktörlerin etkisi incelenmemiştir.

Saldiran vd., alt ekstremite yaralanmasından sonraki 3-12 ay aralığındaki, farkl spor disiplinlerine katılan sporcuların yaralanma geçirmeyen sporculardan daha fazla hareket korkusu yaşadıklarını bulmuştur. ${ }^{23}$ Çalışmamızda ise sağlıklı elit futbolcular ile akut, subakut, persistan yaralanma evresindeki sporcuların hareket korkusu seviyelerinde fark belirlenmemiştir. Çalışma grubumuzun aktivite seviyesinin diğer çalışmadan ${ }^{23}$ daha yüksekte olması sağlıklı grup ile alt ekstremite yaralanması geçiren gruplar arasında hareket korkusu sonuçlarında farkın oluşmamasını sağlamış olabilir. Çünkü aktivite seviyesi orta ya da düşük seviyede olan bireylerin ağriya verebilecekleri yanıtın 'ağrıdan kaçınma' olması beklenirken ${ }^{24}$, elit düzeydeki sporcuların aynı duruma 'kaçınmaya dayanma' cevabı vermeleri beklenmektedir. ${ }^{25}$

Literatürde, yüksek seviyedeki hareket korkusunun, ağrı yoğunluğunun ve aktivitede yetersizliğin güçlü kanıtlarla ilişkili olduğu raporlanmıştır. ${ }^{3}$ Luque-Suarez vd. ise kronik kas-iskelet sistemi ağrısı bulunan bireyler arasında hareket korkusu daha yüksek olanların daha düşük yaşam kalitesine sahip olduğu belirlemiştir. ${ }^{3}$ Ağrının ve hareket korkusunun, öz yeterlilik ve psikososyal stres durumlarını etkileyerek aktivite kısitlamasına ve aktivitede yetersizliğe neden olabileceği tartışılan bir diğer konudur. ${ }^{12}$ Diğer yandan egzersiz öz yeterliliği, engellilik durumunda ve kronik hastalık varlığında bile fiziksel aktiviteye katılım miktarı ile ilişkili bulunmuştur. ${ }^{26,27}$ Denison vd.'ye göre subakut ve kronik kas-iskelet sistemi ağrısı olan hastalarda hareket korkusu düzeyinden ziyade öz yeterlilik düzeyi, fonksiyonel yeterlilik düzeyinin en önemli etkileyicidir. ${ }^{13}$ Ancak çalışmamızdaki elit futbolcuların yaralanma sonrasında fiziksel aktiflikte yetersizlik ve ölçeğin tüm alt boyutlarında etkilenme yaşamasına rağmen hareket korkusu geliştirmediği ve egzersiz öz yeterliliğinde kayıp yaşamadığı bulunmuştur. $\mathrm{Bu}$ sonuçların çalışmamıza katılan bireylerin sportif aktivite düzeyinin çok yüksek olmasından ve yaralanmanin ciddiyet seviyesinin cerrahi gerektirmemesinden kaynaklanabileceği düşünülmüştür.

\section{Limitasyonlar}

Çalışmamızda cinsiyetin, yaşın, aktivite seviyesinin, spor disiplinin ve yaralanma ciddiyetinin (cerrahi gerektirmeyen) homojen tutulması güçlü yönlerimizdendir. Ayrıca elit erkek futbolcularda kas-iskelet sistemi yaralanması sonrada yaşanan fiziksel aktiflikte yetersizliğin hem hareket korkusu hem de egzersiz öz yeterliliği ile etkileşiminin incelenmesi literatürde bulabildiğimiz kadarıla ilktir. Fakat, futbolcuların anket sorularına verdiği beyanların esas kabul edilerek elde edilmesi kısitlılıklarımızdandır.

\section{Sonuç}

Sonuç olarak elit erkek futbolcularda cerrahi gerektirmeyen alt ekstremite yaralanması sonrası, fiziksel aktiflikte yetersizliği gözlenmiş ancak hareket korkusu davranışında ve egzersiz öz yeterliliğinde değişim olmamıştır. Ayrıca yaralanma sonrasında geçen zamana göre bu faktörler farklılık göstermemiştir. Mevcut çalışmanın sonuçlarına göre bu seviyedeki sporcularda alt ekstremite kas-iskelet sistemi yaralanması geçirildikten sonra fiziksel aktiflikte yetersizliğinin giderilmesine odaklanacak tedavi planlarının çizilmesi önerilebilir.

\section{Teşekkür: Yok}

Araştırmacıların Katkı Oranı Beyanı: SE: Çalışma tasarımı, veri toplama, veri analizi, makale yazma, kritik gözden geçirme; ZB: Çalışma tasarımı, veri toplama, kritik gözden geçirme; FB: çalışma tasarımı, veri toplama, kritik gözden geçirme; MB: veri 
toplama, kritik gözden geçirme; GK: Çalışma tasarımı, kritik gözden geçirme; CÇ: çalışma tasarımı; veri toplama-analizi, kritik gözden geçirme.

Çıkar Çatışması: Yok.

Finans: Yok.

Etik Onay: $B u$ araştırma protokolü Süleyman Demirel Üniversitesi Klinik Araştırmalar Etik Kurulu (sayl: 127, tarih: 30.04.2020) tarafindan onaylandi.

\section{KAYNAKLAR}

1. Cetin C, Ercan S, Calım B. Analysis of sports injuries in a professional football club. Med dello Sport. 2020;73:107-116

2. Jones S, Almousa S, Gibb A, et al. Injury Incidence, Prevalence and severity in highlevel male youth football: a systematic review. Sports Med. 2019;49:1897-1899.

3. Luque-Suarez A, Martinez-Calderon J, Falla D. Role of kinesiophobia on pain, disability and quality of life in people suffering from chronic musculoskeletal pain: A systematic review. Br J Sports Med. 2019;53:554-559.

4. Smith BE, Hendrick P, Bateman M, et al. Musculoskeletal pain and exercise Challenging existing paradigms and introducing new. $\mathrm{Br} \mathrm{J}$ Sports Med. 2019;53:907-912.

5. Denison E, Åsenlöf $\mathrm{P}$, Sandborgh $\mathrm{M}$, et al. Musculoskeletal pain in primary health care: subgroups based on pain intensity, disability, self-efficacy, and fear-avoidance variables. J Pain. 2007;8:67-74.

6. Shin YH, Hur HK, Pender NJ, et al. Exercise self-efficacy, exercise benefits and barriers, and commitment to a plan for exercise among Korean women with osteoporosis and osteoarthritis. Int J Nurs Stud. 2006;43:3-10.

7. Kroll T, Kehn M, Ho P-S, et al. The SCI Exercise Self-Efficacy Scale (ESES): development and psychometric properties. Int J Behav Nutr Phys Act. 2007;4:1-6.

8. Kettunen E, Kari T, Makkonen M, et al. Digital coaching among university students with low levels of physical activity: a quantitative intervention study on exercise self-efficacy. In 2019. doi: 10.18690/978-961-286-280-0.45.

9. Hsu CJ, Meierbachtol A, George SZ, et al. Fear of reinjury in athletes: implications for rehabilitation. Sports Health. 2017;9:162-167.

10. Bränström H, Fahlström M. Kinesiophobia in patients with chronic musculoskeletal pain:
Differences between men and women. J Rehabil Med. 2008;40:375-380.

11. Perrot S, Trouvin AP, Rondeau V, et al. Kinesiophobia and physical therapy-related pain in musculoskeletal pain: A national multicenter cohort study on patients and their general physicians. Jt Bone Spine. 2018;85:101107.

12. Damsgard E, Thrane G, Anke A, et al. Activityrelated pain in patients with chronic musculoskeletal disorders. Disabil Rehabil. 2010;32:1428-1437.

13. Denison E, Åsenlöf P, Lindberg P. Self-efficacy, fear avoidance, and pain intensity as predictors of disability in subacute and chronic musculoskeletal pain patients in primary health care. Pain. 2004;111:245-252.

14. Artus M, Campbell P, Mallen CD, et al. Generic prognostic factors for musculoskeletal pain in primary care: A systematic review. BMJ Open. 2017;7:e012901.

15. Wong EML, Chan SWC, Chair SY. Effectiveness of an educational intervention on levels of pain, anxiety and self-efficacy for patients with musculoskeletal trauma. J Adv Nurs. 2010;1120-1131.

16. Söderlund A, Åsenlöf P. The mediating role of self-efficacy expectations and fear of movement and (re)injury beliefs in two samples of acute pain. Disabil Rehabil. 2010;32:2118-2126.

17. Tegner Y, Lysholm J. Rating systems in the evaluation of knee ligament injuries. Clin Orthop Relat Res 1985:43-49.

18. Baker R, Burton D, Pickering $M$, et al. Confirmatory factor analysis of the disablement in the physically active scale and preliminary testing of short-form versions: a calibration and validation study. J Athl Train. 2019;54:302-318.

19. Tunca Yilmaz Ö, Yakut Y, Uygur F,et al. Turkish version of the tampa scale for kinesiophobia and its test-retest reliability [Tampa kinezyofobi ölçeǧi'nin Türkçe versiyonu ve testtekrar test güvenirliği]. Fiz Rehabil. 2011;22:44-49.

20. Bozkurt N. Meme kanseri hastalarında egzersiz öz yeterlilik ölçeğinin Türkçe geçerlilik ve güvenirliğinin incelenmesi. Ege Üniversitesi; 2009.

21. Flanigan D, Everhart J, Pedroza A, et al. Fear of reinjury (kinesiophobia) and persistent knee symptoms are common factors for lack of return to sport after anterior cruciate ligament reconstruction. Arthrosc J Arthrosc Relat Surg. 2013;29:1322-1329.

22. Norte G, Solaas H, Saliba S, et al. The relationships between kinesiophobia and clinical outcomes after ACL reconstruction differ by self-reported physical activity engagement. Phys Ther Sport. 2019;40:1-9. 
23. Çevik Saldıran T, Atıcı E, Öztürk Ö, et al. Lower limb injury history in elite athletes: relationship with kinesiophobia and effect on physical performance. Turkiye Klin J Sport Sci. 2020;12:1-8.

24. Leeuw M, Goossens MEJB, Linton SJ, et al. The fear-avoidance model of musculoskeletal pain: Current state of scientific evidence. J Behav Med. 2007;30:77-94.

25. Hasenbring M, Verbunt J. Fear-avoidance and endurance-related responses to pain: new models of behavior and their consequences for clinical practice. Clin J Pain. 2010;26:747-753.
26. te Velde SJ, Lankhorst K, Zwinkels M, et al. Associations of sport participation with selfperception, exercise self-efficacy and quality of life among children and adolescents with a physical disability or chronic disease-a crosssectional study. Sport Med - Open. 2018;4:1-11.

27. Kooijmans H, Post M, Motazedi E, et al. Exercise self-efficacy is weakly related to engagement in physical activity in persons with long-standing spinal cord injury. Disabil Rehabil. 2019;66:1120-1131. 